\title{
Enhancement of Distance Relay Performance in Transmission Line Compensated by Series Capacitor Protected by MOV
}

\author{
Prof. Dr. Maamoon F. AL-Kababjie Dhafer. A . AL_Nuaimy \\ Department of Electricity \\ University of Mosul \\ Mosul, Iraq \\ Al_kababjie@yahoo.com \\ almohands_dm@yahoo.com
}

\begin{abstract}
The normal distance relay face many challenges in a series compensated transmission lines the distance relay may give incorrect decision. This paper present a digital distance relay designed by using wavelet transform (WT) to work with this compensated transmission lines. The relay have another features to recognize between fault and disturbance cases, classify fault types and giving the trip signal to circuit breaker in a time less than period quarter. The relay has been tested for both simulation cases and practically cases by simulation transmission lines board in the lab.

Index Terms: Distance relay, fault detection , Series-Compensated Lines Protection, wavelet transform, MOV

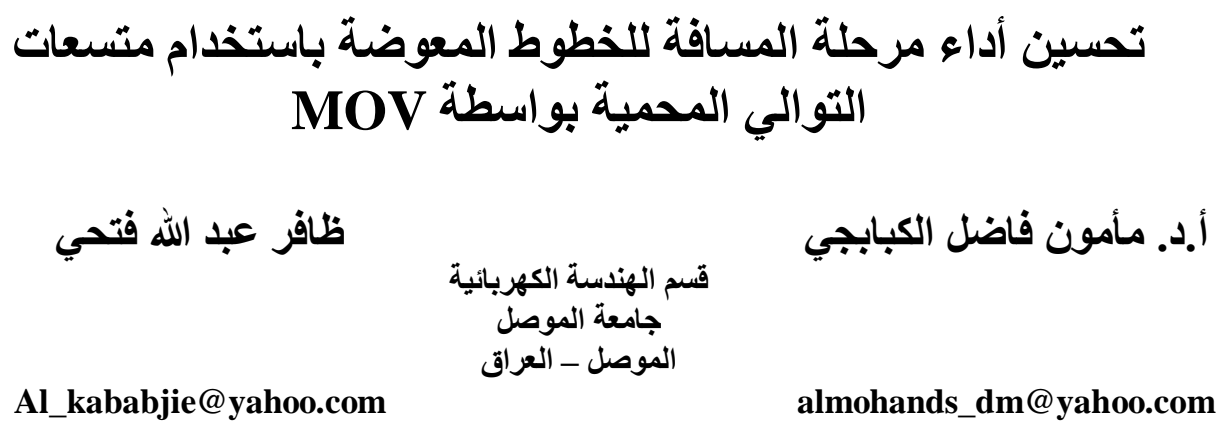

Al_kababjie@yahoo.com

almohands_dm@yahoo.com

\section{الخلاصة}

مرحلة المسافة الاعتيادية تواجه عدة تحديات عند العمل في خطوط نقل الطاقة الكهربائية المعوضة بافئ باستخدام

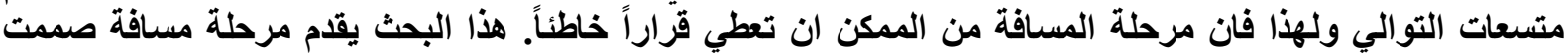

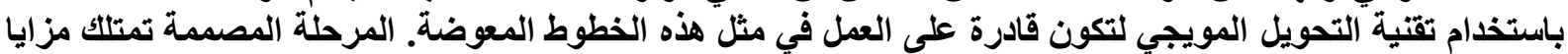

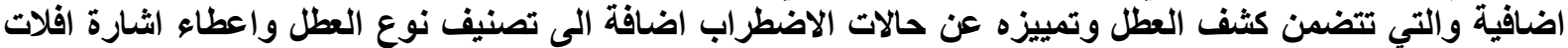

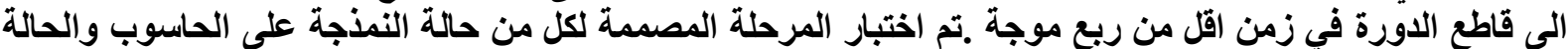
العملية في مختبر خط النقل.
\end{abstract}




\section{Introduction:}

There are several types of electric devices affected by faults and disturbances, distance relay is one of these devices. This relay is an important device to keep protection and ensuring accuracy for power system .Its good feature gives a primary and back up protection for transmission line. The main target of these relay is to calculate impedance at the fundamental frequency between the relay point and the fault point. According to this impedance, the fault will determine if it was inside or outside the protection zones. This impedance is calculated from the measured voltage and current signals at the relay position [1].

The technical reasons behind installing Series Capacitors (SCs) on long transmission lines are Increased transmittable power, improved system stability, reduced transmission losses, enhanced voltage control and more flexible power flow control.as well as Environmental concerns and direct cost benefits. SCs and their overvoltage protection devices when installed on a transmission line, create many problems for protection relays and fault locators.

Operating conditions for protective relays become unfavorable and include many problems such as voltage and/or current inversion, sub- harmonic oscillations, and additional transients caused by the air gaps triggered by thermal protection of the metal oxide varistors (MOVs).

Overreaching of distance relays due to series compensation is probably the most critical and known consequence of SCs. The opposite may happen as well: a distance relay may fail to detect a low-current fault on the protected line [2].

To protect the series capacitor from over voltages that develop in the case of shortcircuit faults, metal oxide varistors (MOVs) are used in parallel with the capacitor. The MOV is a non-linear resistor that limits the voltage across the capacitor during a fault condition. When the fault is cleared, the MOV allows almost instantaneous reinsertion of the capacitor into the transmission line [3].

In this work wavelet transform (WT) used to design a digital distance relay, Wavelets are a new mathematical tool for signal processing. Compared to Fourier analysis, which relies on a single basis function, a number of basis functions of a rather wide functional form are available in wavelet analysis. The basic idea in wavelet transform (WT) is to choose a suitable wavelet function "mother wavelet" and then perform analysis using shifted and dilated versions of this wavelet. Wavelet can be chosen with very desirable frequency and time characteristics as compared to Fourier techniques. The basic difference is that, in compare to the short time Fourier transform which uses a single analysis window, the WT uses short windows at high frequencies and long windows at low frequencies. The basic functions in WT employ time compression or dilation rather than a variation in time frequency of the modulated signal [1].

\section{Series Capacitor Protection}

The MOV is a nonlinear resistive device, which starts to conduct at certain instantaneous voltage and ceases to conduct when the voltage falls below the same voltage at each half cycle of the power frequency. The non-linear voltage-current characteristic of the MOV allows it to provide overvoltage protection for the capacitor when connected in parallel with it. The MOV keep the voltage across the capacitor within the allowable range of the capacitor by allowing a self-regulating amount of current through itself automatically.

Figure 1 shows the elements used to protect the series capacitor bank against over voltages. The MOV itself is protected against high absorption of energy by using a bypass switch. As the MOV conducts current, energy accumulates within the MOV itself. The MOV 
has a maximum amount of energy that it can absorb before it breaks down. Hence, the MOV is bypassed at a preset energy level to avoid break down. The bypass breaker connects when the energy absorbed by the MOV is greater than the preset value. This bypasses both the MOV and series capacitors and re-inserts them when the energy falls below the preset value. The impedance seen by the relay transits quickly from compensated impedance to uncompensated impedance during severe shortcircuits faults.

An equivalent series capacitive reactance and resistance of a MOV protected series capacitor as a function of normalized line current based on the capacitor's protective level current is given by the model in fig. 2 which $\mathrm{i}$ used in this work.

The MOV protected series capacitor equivalent model parameters under short-circuit currents can be obtained by the following equations :

$\mathrm{R}_{\mathrm{mov}-\mathrm{sc}}=\mathrm{X}_{\mathrm{sc}}\left(0.0745+0.49 e^{-0.243 . J P U}-35 . e^{-5.1 p u}-0.6 e^{-1.41 p u}\right)$

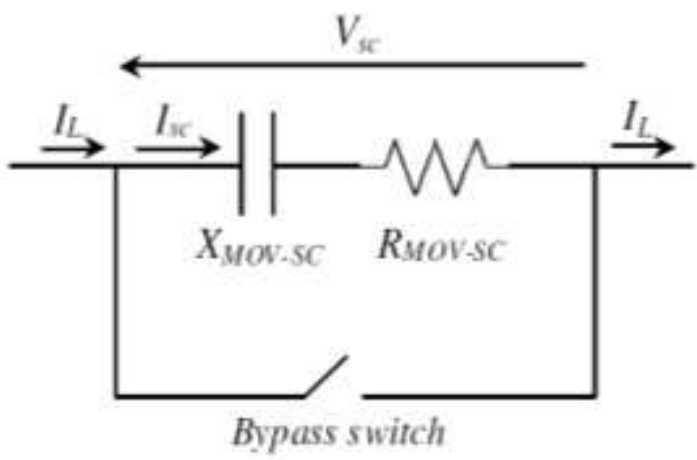

Fig. (2): Eauivalent model.

$\mathrm{X}_{\mathrm{mov}-\mathrm{sc}}=\mathrm{X}_{\mathrm{sc}}\left(0.10-0.005749 .1 p u+2.088 \cdot e^{-0.85661 p u}\right)$

Where, Ipu is fault current expressed in per unit of capacitor protective level current [4].

\section{Series Compensated Lines Protection Challenges}

The normal distance relay face many challenges in a series compensated transmission lines from these challenges voltage inversion, current inversion and the error in the impedance.

A voltage inversion is a change of 180 degrees in the voltage phase angle. For elements responding to phase quantities, voltage inversion can occur for a fault near a series capacitor if the impedance from the relay to the fault is capacitive rather than inductive. Voltage inversion may affect directional and distance elements. In general, phase relays that take voltage information from the fault side of the series capacitor will correctly declare the fault direction. Relays measuring the voltage from the other side of the capacitor with respect to the fault location may incorrectly declare the fault direction.

A current inversion occurs on a series-compensated line when, for an internal fault, the equivalent system at one side of the fault is capacitive and the equivalent system at the other side of the fault is inductive. The current flows out of the line at one terminal, which is referred to as current outfeed. The currents are approximately 180 degrees out of phase.

Series compensation cause errors in the impedance that distance elements calculate. The series capacitor modifies the line impedance that the relay estimates. Furthermore, subharmonic-frequency oscillations cause the impedance estimation to oscillate. The basic problem is that the impedance calculation depends on the state of the capacitor protection [5]. 


\section{Phasors Estimation}

Theoretically, the phasors should be estimated from the sixth decomposition level $(0-78.125 \mathrm{~Hz})$. Since the compact support wavelets do not have ideal cutoff frequency characteristics, the phasors cannot be estimate from this level. From the fifth level of decomposition the phasor (magnitude and angle) of each signal can be estimated by using the approximation coefficients vector of A5 as discussed below. The phasors of the measured voltage and current signals at the fundamental frequency can be estimated by using a unity amplitude 50- $\mathrm{Hz}$ sinusoidal reference signal (X1), sampled at the same sampling rate as the measured signals $(10 \mathrm{kHz})$ for simulation and $(12.8 \mathrm{KHz})$ for practical. For each data window, the sinusoidal reference signal and the measured signals are decomposed into fifth levels of decomposition using "db4" mother wavelet. As aforementioned, the phasors are estimated from the approximate coefficients A5 vector of the fifth decomposition level. The magnitude and angle with respect to the reference sinusoidal signal for each measured signal can be estimated using the basic vector mathematics. For example, if the approximate coefficient vector of the fifth decomposition level of the sinusoidal reference is A5X1 and for one of the measured Signals is A5S , then the angle (theta) between the two vectors is defined as:

$\theta=\cos ^{-1}\left(\frac{A 5 X 1 \cdot A 5 S}{|A 5 X 1 \| A 5 S|}\right)$

Where (A5X1•A5S ) is the dot product of the two vectors and (|A5X1\|A5S $\mid)$, are the norms of the two vectors.

A new unity amplitude sinusoidal signal (X2) with a phase shift equal to the calculated angle (theta) is constructed and sampled at the same previous sampling frequency. The new signal is then decomposed into fifth decomposition levels using the same mother wavelet as used before. Using the fifth approximate coefficient vector A5X2 of this constructed sinusoidal signal, and the fifth approximate coefficient vector A5S of the measured signal, the magnitude $\mathrm{Y}$ of the measured signal can be defined as:

$$
Y=\frac{\left|\begin{array}{llll}
1 \mid A & 5 & S
\end{array}\right|}{|A 5 x \quad 2|}
$$

The same procedure can be used for all the other measured signals to estimate their phasors [6][1].

\section{Simulation Tests}

In order to investigate the applicability of the proposed wavelet transform distance relay, a simulation of transmission line model for different disturbances and different faults is formulated by using MATLAB. The system of simulation shown in fig. (3). by taking several cases of fault on the transmission line with different fault

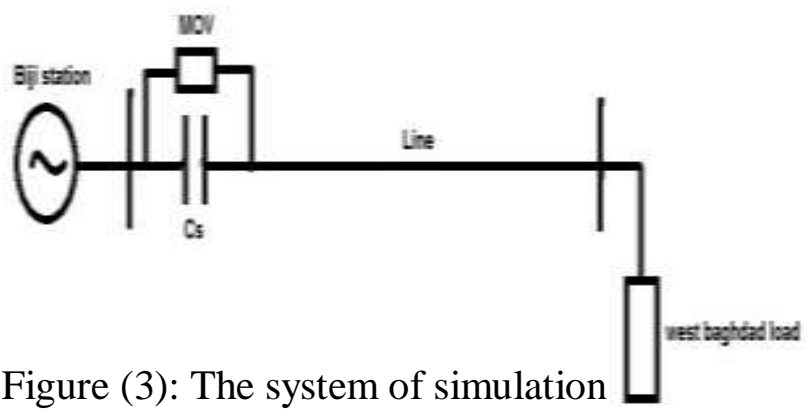
locations and many disturbance cases the thresholds is chosen by calculate the maximum peak of current for each phase current .so the value of the threshold (Thl) is (2.355)Amp. The fault is detected and recognized from other disturbances and its type classified by comparing the peak value of the currents as well as indicate the fault zone by using wavelet transform as in section 4. Fig (4) show the flow chart for the designed distance relay . 


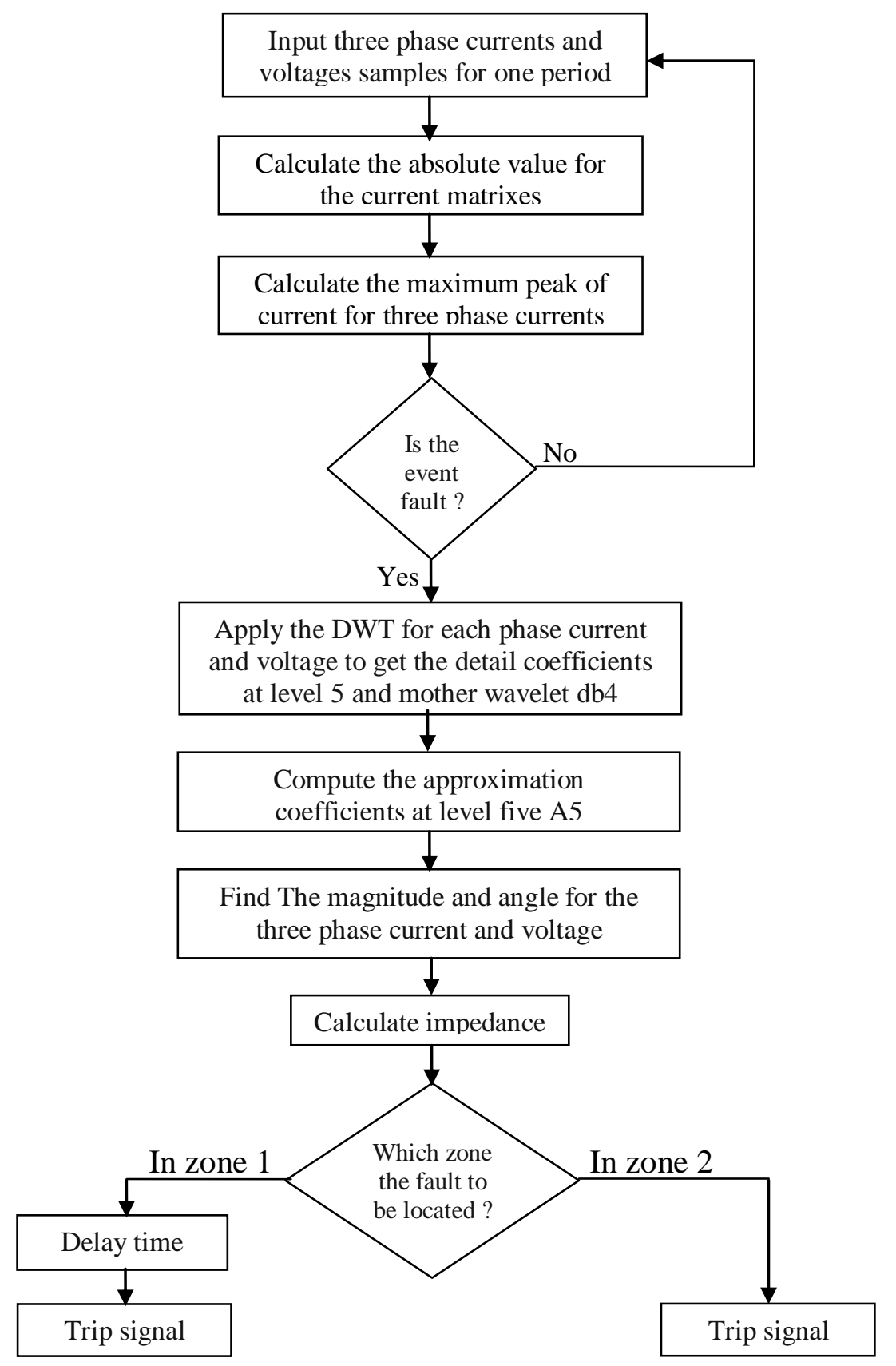

Figure (4): The flow chart for the designed distance relay

\section{Simulation Results}

In this section, some typical results illustrate the performance of the protection technique being developed . single line to ground, double line to ground and three line to ground faults at $(10 \%, 50 \%, 90 \%)$ from the length of the transmission line shown in fig (3) are implemented .

Figures 5.6.7. Show the relation between the fault location on the $\mathrm{x}$-axis with maximum peak for three phase currents on the $\mathrm{Y}$-axis where (pa) is the maximum peak of current for phase (A) and (pb) is the maximum peak of current for phase (B) and (pc) is the maximum 
peak of current for phase $(C)$. from the obtained results one can realized that the maximum peak of currents for the faulted phases are greater than the threshold value (Th1=2.355 Amp) while the maximum peak of currents for unfaulted phases are less than the threshold value (Th1=2.355 Amp), so the relay will respond to the faulted phase or phases .
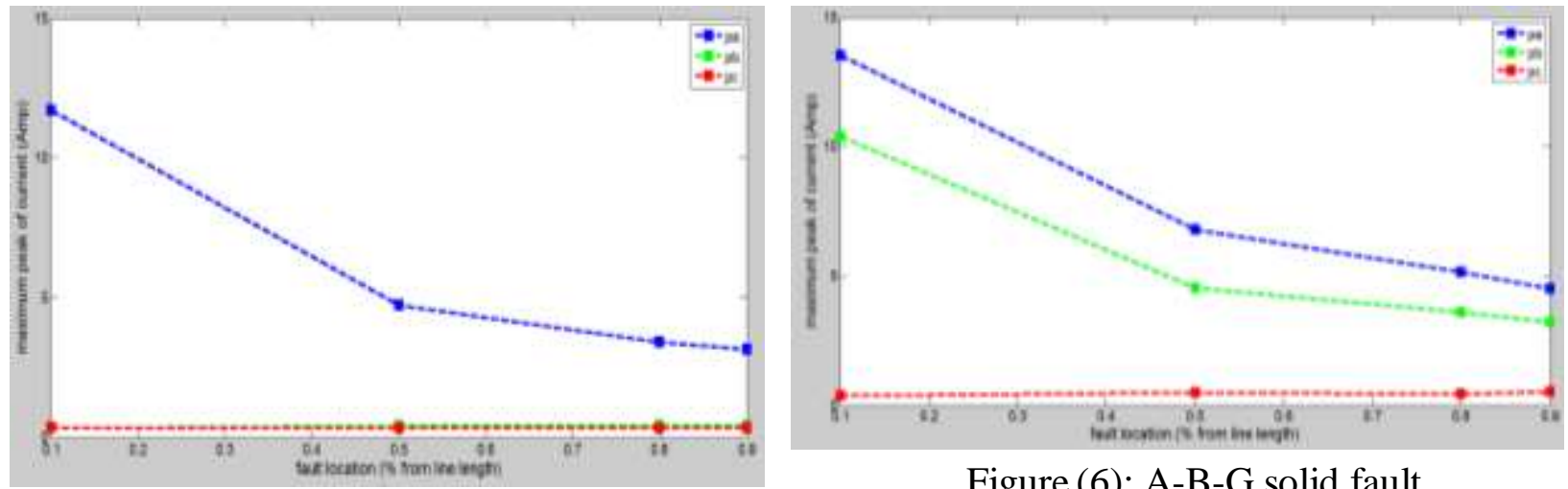

Figure (5): A-G solid fault

Figure (6): A-B-G solid fault

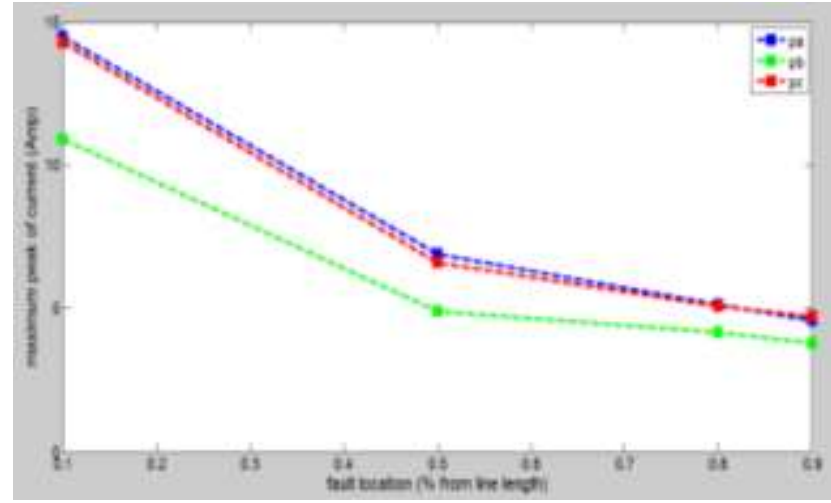

Figure (7): A-B-C-G solid fault

Table (1) shows the Simulation results of the disturbances on the line system of fig. (3)

Table (1): Simulation results of the disturbances on the line system of fig. (3)

\begin{tabular}{|c|c|c|c|c|}
\hline Type of the disturbance & $\begin{array}{c}\mathrm{Pa} \\
(\mathrm{Amp})\end{array}$ & $\begin{array}{c}\mathrm{Pb} \\
(\mathrm{Amp})\end{array}$ & $\begin{array}{c}\text { Pc } \\
(\mathrm{Amp})\end{array}$ & Trip \\
\hline $\begin{array}{c}\text { Add load of 50\% from the initial load } \\
\text { at the end of the line at } \mathrm{t}=1 \mathrm{sec}\end{array}$ & 0.7655 & 0.7697 & 0.7898 & 0 \\
\hline $\begin{array}{c}\text { Add generator with } 50 \% \text { load from } \\
\text { the baiji station side at } \mathrm{t}=1 \mathrm{sec}\end{array}$ & 0.7453 & 0.7806 & 0.7852 & 0 \\
\hline
\end{tabular}

From the results shown in table (1) it can be seen that all peak of the currents are less than the threshold value (Th1=2.355 Amp), so the relay will not respond to these disturbance cases.

\section{Practical Results}

The designed relay was tested in the lab by the circuit shown in figure (8.a). The values of thresholds are chosen in the same way in section 5 . The value of the threshold for practical cases was (Th1=4 Amp). Several cases for non fault transient events were tested as well as the 
fault events. The "power pad" device used to forward the practical results using $12.8 \mathrm{KHz}$ sample frequency. figure (8.b) show the practical simulation transmission system.

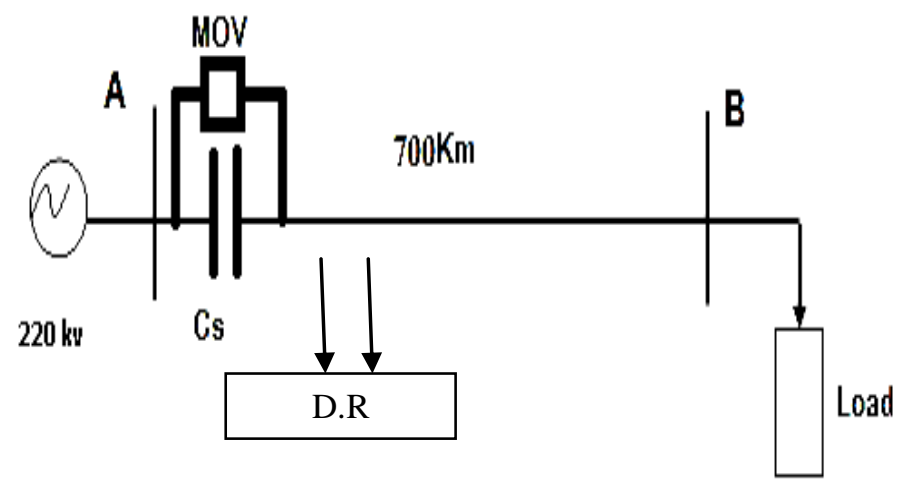

Figure (8.a): Single line diagram for Practical simulation transmission system.

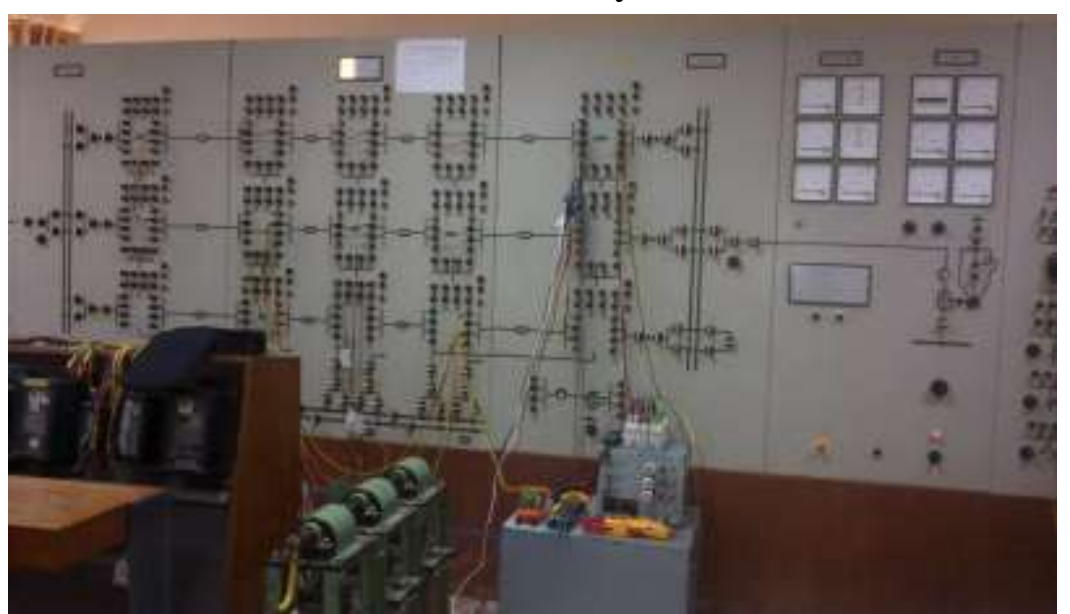

Figure (8.b): Practical simulation transmission system.

Many faults at many locations as a percentage of line length on the transmission line were implemented and the following curves show the results. The practical transmission line information are shown in the appendix.

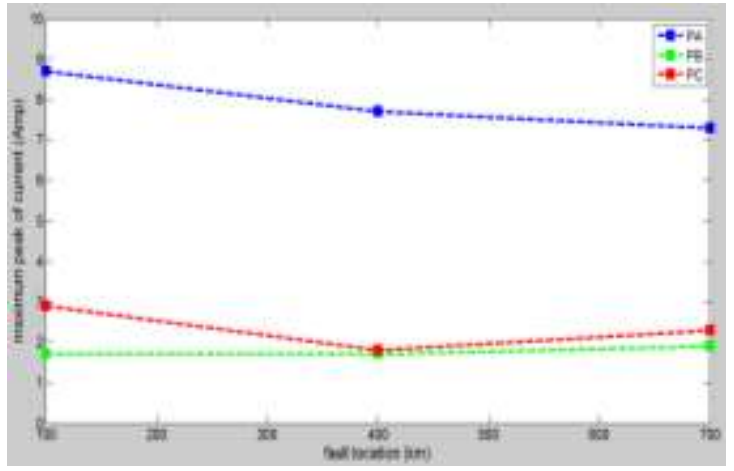

Figure (9): A-G solid fault

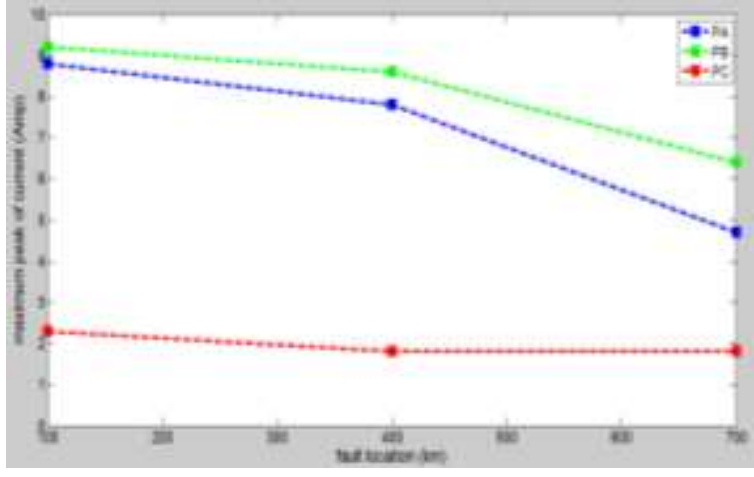

Figure (10): A-B-G solid fault 
Figures 9.10.11.show the relation between the fault location in $(\mathrm{km})$ on the $\mathrm{X}$-axis with maximum peak of currents for three phase currents on the $\mathrm{Y}$-axis. In all figures it is clear that the maximum peak of currents for the faulted phases are greater than the threshold value (Th1 $=4$ Amp) while the maximum peak of currents for unfaulted phases are less than the threshold value (Th1), so the relay will respond to the faulted phase or phases.

Table (2) shows the Results of the

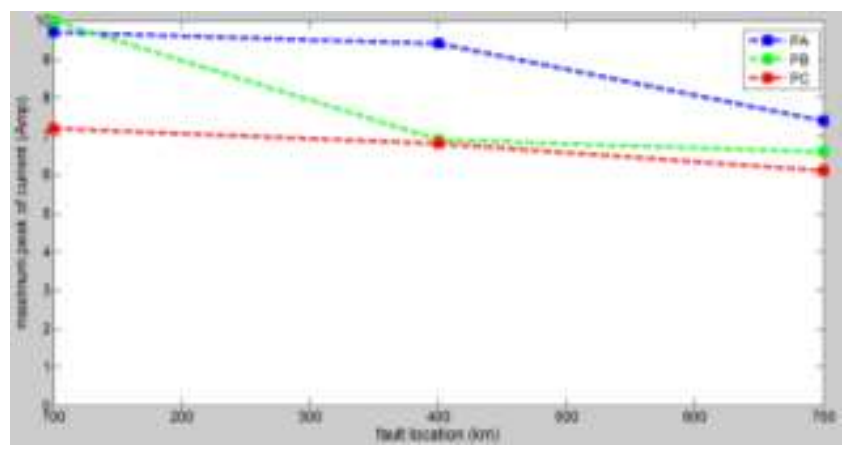

Figure (11): A-B-C-G solid fault disturbances on the lab transmission line

Table (2): Results of the disturbances on the lab transmission line

\begin{tabular}{|c|c|c|c|c|}
\hline Type of the disturbance & $\begin{array}{c}\mathrm{Pa} \\
(\mathrm{Amp})\end{array}$ & $\begin{array}{c}\mathrm{Pb} \\
(\mathrm{Amp})\end{array}$ & $\begin{array}{c}\text { Pc } \\
(\mathrm{Amp})\end{array}$ & Trip \\
\hline $\begin{array}{c}\text { Add load of 96MW to the initial } \\
\text { load at 700km from the line length }\end{array}$ & 2.1 & 1.8 & 2 & 0 \\
\hline $\begin{array}{c}\text { Add load of 96MW to the initial } \\
\text { load at 400km from the line length }\end{array}$ & 2.2 & 1.9 & 1.9 & 0 \\
\hline
\end{tabular}

From the results shown in table (2) it can be seen that all peak of the samples are less than the threshold value (Th1=4 Amp) .

From the results shown in the six previous figures we can see that the designed relay worked by same principle and same performance for both simulation and practical cases of transmission lines.

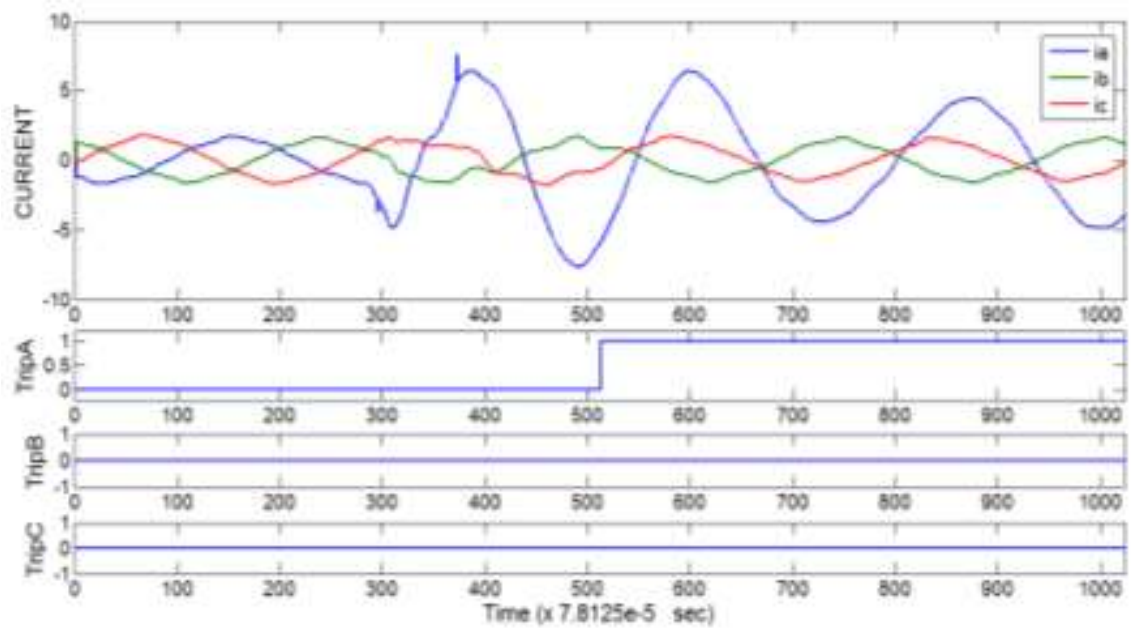

Figure (12): practical results of three phase currents and trip signals for A-G fault on $400 \mathrm{~km}$ length

Fig. 12 and fig. 13 show the three phase currents and trip signals for both practical and simulation cases. from fig. 12 we can see the distortion existence in the practical current signal, while the simulation waves, fig.13. without distortion . in spite of this distortion the designed relay worked in correctly and gave a true decision in both cases. 
AL-KABABJIE: Enhancement of Distance Relay Performance in .....

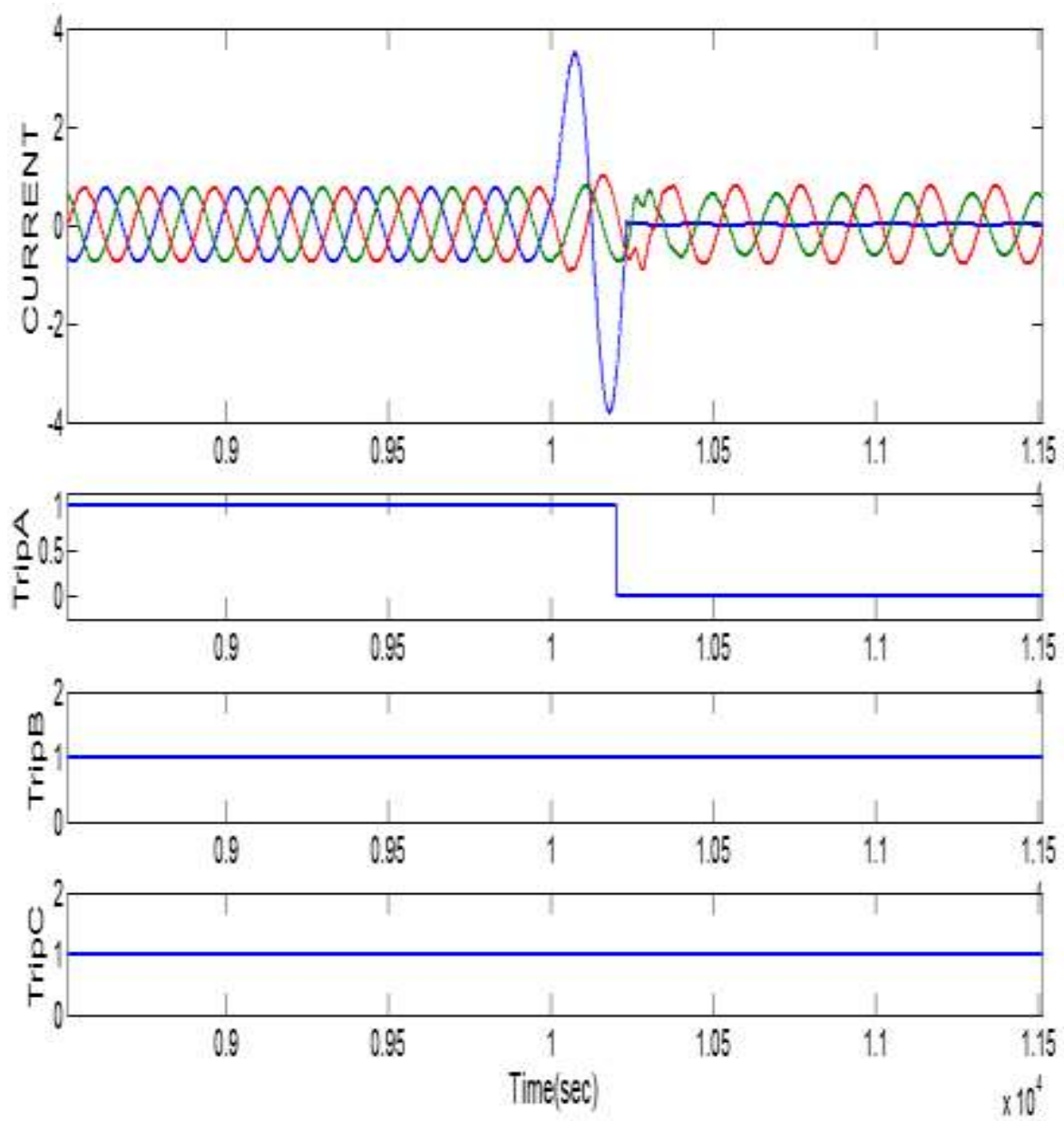

Figure (13): simulation results of three phase currents and trip signals for $\mathrm{A}-\mathrm{G}$ fault on $\mathrm{k}=80 \%$ from the line length

Table (3) shows that the designed distance relay was operate correctly in all the faults at the compensated lines while we note the overreach in the relay when it is install in the normal line.

Table (3): Comparison between the relay operation in normal line and compensated line.

\begin{tabular}{|c|c|c|c|c|}
\hline \multirow[t]{2}{*}{ The system } & \multirow[t]{2}{*}{ The fault type } & \multirow[t]{2}{*}{ The fault location } & \multicolumn{2}{|c|}{$\begin{array}{c}\text { The relay state } \\
\text { correct operation }: \sqrt{ } \\
\text { mal operation (overreach): } X\end{array}$} \\
\hline & & & Normal line & Compensated line \\
\hline \multirow{6}{*}{$\begin{array}{c}\text { (Baiji-Baghdad west) } \\
\text { system }\end{array}$} & \multirow[t]{2}{*}{$\mathrm{AG}$} & Zone1 & $\sqrt{ }$ & $\sqrt{ }$ \\
\hline & & Zone2 & $\mathrm{X}$ & $\sqrt{ }$ \\
\hline & \multirow[t]{2}{*}{$\mathrm{ABG}$} & Zone1 & $\sqrt{ }$ & $\sqrt{ }$ \\
\hline & & Zone2 & X & $\sqrt{ }$ \\
\hline & \multirow[t]{2}{*}{ ABCG } & Zone1 & $\sqrt{ }$ & $\sqrt{ }$ \\
\hline & & Zone2 & $\mathrm{X}$ & $\sqrt{ }$ \\
\hline \multirow{6}{*}{ The practical system } & \multirow[t]{2}{*}{$\mathrm{AG}$} & Zone1 & $\sqrt{ }$ & $\sqrt{1}$ \\
\hline & & Zone2 & $\mathrm{X}$ & $\sqrt{ }$ \\
\hline & \multirow[t]{2}{*}{$\mathrm{ABG}$} & Zone1 & $\sqrt{ }$ & $\sqrt{ }$ \\
\hline & & Zone2 & $\mathrm{X}$ & $\sqrt{ }$ \\
\hline & \multirow[t]{2}{*}{ ABCG } & Zone1 & $\sqrt{ }$ & $\sqrt{ }$ \\
\hline & & Zone2 & $\mathrm{X}$ & $\sqrt{ }$ \\
\hline
\end{tabular}




\section{Conclusion}

The designed distance relay tested with both computer simulation program and practically on the transmission line board in the lab. This distance relay proved its capability to work by high speed (time less than period quarter)and high accuracy for detecting the faults. Its classify the fault type and recognize it from the disturbance cases. The relay has the ability to indicate the fault position whether it is in zone one or not and take the decision to disconnect the system immediately, or in zone two, so it take the action after a delayed time.

\section{References}

[1] A. H. Osman and O. P. Malik, "Transmission Line Distance Protection Based On Wavelet Transform". IEEE Trancaction On Power Delivery, Vol. 19, No. 2, April 2004

[2] Bogdan Kasztenny, "Distance Protection Of Series Compensated Lines: Problems And Solutions", 28th Annual Western Protective Relay Conference, October, 2001.

[3] A. Gopalakrishnan', D. M. MacGregor'and T. Tho, "Implementation of A Mov Computation Method Within A Protection System Simulation" 'Electrocon International Inc., USA; 'Svenska Kraftnat, Sweden

[4] M. Zellagui and A.Chaghi, "Impact of series compensation (Sc) on the MHO distance Relay in Algerian $220 \mathrm{Kv}$ Transmission Line", Canadian journal on Electrical and Electronics Engineering,Vol.2, No.6, June 2011.

[5] Héctor J. Altuve, Joseph B. Mooney, and George E. Alexander,"Advances in SeriesCompensated Line Protection", IEEE, 2009.

[6] Dr. Maamoon F. AL_Kababjie, Nagham. H. AL_ Namee," Disturbance Performance Improvment of Distance Relay With Aid of Wavelet", 2010 7th International MultiConference on Systems, Signals and Devices, 2010. Amman.

\section{Appendix}

Biji station information:

Generation value $(\mathrm{MW})=750$

Short circuit level $(\mathrm{MVA})=11100$

$\mathrm{X} / \mathrm{R}=3$

$\mathrm{V}(\mathrm{kv})=400$

west Baghdad load:

active power $(\mathrm{MW})=310$

reactive power $(\mathrm{MVAR})=35$

Compensation degree $=70 \%$

Transmission line parameters:

$\mathrm{R} 1=0.034672 \Omega / \mathrm{km}$

$\mathrm{L} 1=1 \mathrm{e}-3 \mathrm{H} / \mathrm{km}$

$\mathrm{C} 1=23.23 \mathrm{nf} / \mathrm{km}$

Compensation degree $=53 \%$

The work was carried out at the college of Engineering. University of Mosul 